\title{
It is a marathon rather than a sprint: an initial exploration of unmet needs and support preferences of caregivers of children with $\mathrm{SCl}$
}

\author{
Susan L. Ryerson Espino ${ }^{1,2}$ - Erin H. Kelly ${ }^{1,3,4} \cdot$ Anne Rivelli $^{4}$ - Kathy Zebracki ${ }^{1,5}$ - Lawrence C. Vogel ${ }^{1,6}$
}

Received: 1 February 2017 / Revised: 25 September 2017 / Accepted: 28 September 2017 / Published online: 30 November 2017

(c) International Spinal Cord Society 2018

\begin{abstract}
Study design Focus group study.

Objectives Explore unmet needs and support preferences of caregivers of youth with spinal cord injury (SCI).

Setting One pediatric specialty rehabilitation hospital system in the United States.

Methods Four focus groups were conducted with a convenience sample of 26 caregivers who were primarily mothers (96\%) and married (65\%), and had at least some college education (85\%). Children living with SCI were on average 12.8 years old $(\mathrm{SD}=3.3,8-18)$. The average age of injury was 4.7 years $(\mathrm{SD}=4.4,0-16.2)$; mean injury duration was 8.2 years $(\mathrm{SD}=$ $3.9,2-16) ; 77 \%$ had paraplegia; and 58\% were male. Focus groups were digitally recorded, transcribed verbatim, and coded using thematic analysis and NVivo.

Results Qualitative data highlighted caregiver perspectives on unmet needs relating to two phases of care: acute and rehabilitation vs. current life with SCI, and two kinds of stressors: those associated with SCI and care vs. those related to other areas of the caregivers' lives, especially their families. Caregivers described stressful interactions with care systems and community services, articulated several concerns regarding well-being of family members, and noted that both they and their children with SCI experienced isolation. Caregivers articulated preferences for additional support from professionals and peers.

Conclusions Data suggest the need for ongoing caregiver interventions and strengthened family-centered care systems, including professional assistance navigating health systems and peer support. Intervention development would benefit from further qualitative data collection with additional caregivers of youth with SCI, including multiple family members, and families from more diverse care settings.
\end{abstract}

\section{Introduction}

Youth with spinal cord injuries (SCIs) have complex health and daily living needs that are generally managed by

Electronic supplementary material The online version of this article (https://doi.org/10.1038/s41393-017-0022-6.) contains supplementary material, which is available to authorized users.

Susan L. Ryerson Espino

srespino@gmail.com

1 Shriners Hospitals for Children, Chicago, IL, USA

2 Marquette University, Milwaukee, WI, USA

3 American Academy of Pediatrics, Elk Grove Village, IL, USA

4 University of Illinois, Chicago, IL, USA

5 Northwestern University Feinberg School of Medicine, Chicago, IL, USA

6 Rush Medical College, Chicago, IL, USA caregivers, most often parents [1]. Challenges associated with caregiving across a variety of chronic illnesses and disabilities are widely documented and include the toll on caregiver physical and emotional health and quality of life (QOL) [2]. Attending to the complex health and unmet needs of caregivers is vital to the overall health of the caregiver, as well as the functioning of the child and the entire family unit [3-7]. Lazurus and Folkman's stress and coping model [8] and Pearlin and colleagues' stress process model $[9,10]$ examine the nature of stressors and how internal resources (e.g., coping) and external resources (e.g., social support) can influence how stress impacts health and well-being. Although applied to other types of caregiver research (e.g., Alzheimer's [9] and cancer [11]), the potential utility of these models in helping understand the complexities of caregiving and pediatric SCI has not yet been actualized.

Much of the SCI research to date has explored health and well-being outcomes among caregivers and how caregiver 
health and well-being relate to the well-being of those in their care. For instance, SCI caregiving has been associated with elevated depressive and anxiety symptoms, marital satisfaction, and QOL for the caregiver [12-19]. Further, the mental health of caregivers of youth with SCI has been found to predict child mental health, physical health, adjustment to disability, and QOL [3, 15, 20]. Among families with pediatric SCI, reciprocal relationships have been found between caregiver and child mental health [20], caregiver and youth post-injury post-traumatic stress disorder [14], and caregiver mental health and child healthrelated QOL (HRQOL) [21]. Research has also begun to explore skill sets (i.e., resources) that may mediate the relationship between stressors and outcomes. For example, caregiver tendencies to solve problems impulsively and carelessly predicted lower acceptance of disability among adults with SCI at time of discharge and the occurrence of pressure sores post-discharge [22]. In addition, effective caregiver problem solving predicted increased HRQOL of their children with SCI [3].

Little however has been done to understand the nature of stressors faced by caregivers of youth with SCI, particularly from the perspectives of caregivers themselves. The stress process model offers a comprehensive framework for assessing the nature of caregiving stressors, and distinguishes between primary stressors, which include injury and care demands, and secondary stressors, which include radiating effects extending to other areas of the caregiver's life (e.g., family, employment, and self-care). Understanding the nature of stressors and their particular impact on well-being can help better target intervention efforts.

The purpose of the current study was to gain a better understanding of the stressors experienced by caregivers of youth with SCI, as well as the social supports necessary to address these stressors. Focus groups were conducted to assess caregivers' perspectives on stressors, discussed as "unmet needs," and preferences related to social support. Qualitative research is well suited to documenting personal experiences of those living with chronic health conditions. Through qualitative research, investigators can explore individuals' experiences with health care, understand unmet needs, and foster more nuanced and empathic health care practices that may be overlooked with quantitative inquiry [23-31]. Focus groups are a useful qualitative methodology for exploring the perceptions and experiences of a group of people who share some common interests or characteristics. The group process encourages members to reflect on their views as well as articulate, elaborate, and clarify their own personal experiences in the context of a group of similar peers [23, 32, 33]. Several focused discussions can be conducted with similar participants to explore patterns in perceptions, dialog, interactions, and group dynamics. The ultimate goal of this work was to build upon existing research that examines stress and coping among caregivers and generate ideas for future supports, programs, and research related to the health of caregivers of youth with SCI.

\section{Methods}

\section{Setting}

The current focus group study took place within one pediatric specialty health care system in the United States. The focus groups occurred after a yearlong caregiver support intervention that randomized caregivers to an intervention group (received monthly phone calls from a mental health professional) or control group (received care as usual) and concluded with an in-person parent forum for all caregiver participants. Focus groups took place during this parent forum, with the primary purpose being to obtain caregiver feedback on their intervention experiences [34]. However, a secondary purpose was to assess caregivers' unmet needs and support preferences; these data are the focus of the current manuscript. The study protocol was approved by the Institutional Review Board; all participants consented to participate and ethical procedures were followed regarding the treatment of human subjects and reporting of all research procedures and findings.

\section{Participants}

The current study included caregivers of youth ages 7-17 with SCI who were injured for at least 1 year and participated in the intervention referenced above. Participants were recruited for the intervention from a pediatric specialty health care system and community organizations serving youth and families with disabilities. Forty-one caregivers initially enrolled in the intervention; 1 caregiver withdrew, and 14 of the remaining caregivers were unable to attend the parent forum that occurred at the end of the intervention due to schedule conflicts, travel concerns, work conflicts, and personal and family health concerns.

All caregivers present at the parent forum were invited and agreed to participate in 1 of the 4 focus groups. These 26 caregivers had a mean age of 41.8 years $(\mathrm{SD}=7.7$, Range $=29-63)$ and were primarily mothers $(96 \%)$, and married (65\%); $89 \%$ were Caucasian and $85 \%$ had at least some college education. Their children with SCI had a mean age of 12.8 years at the time of the focus groups $(\mathrm{SD}=3.3$, $8-18)$ and 4.7 years at time of injury (SD $=4.4,0-16.2)$, with a mean injury duration of 8.2 years $(\mathrm{SD}=3.9,2-16)$. Of the 26 children, $58 \%$ were male, $81 \%$ Caucasian, $77 \%$ had paraplegia, $58 \%$ had a complete injury, and $42 \%$ had sustained their injury in a motor vehicle crash. Caregivers were stratified into four groups for focus group participation: those with children with (1) paraplegia and in the 


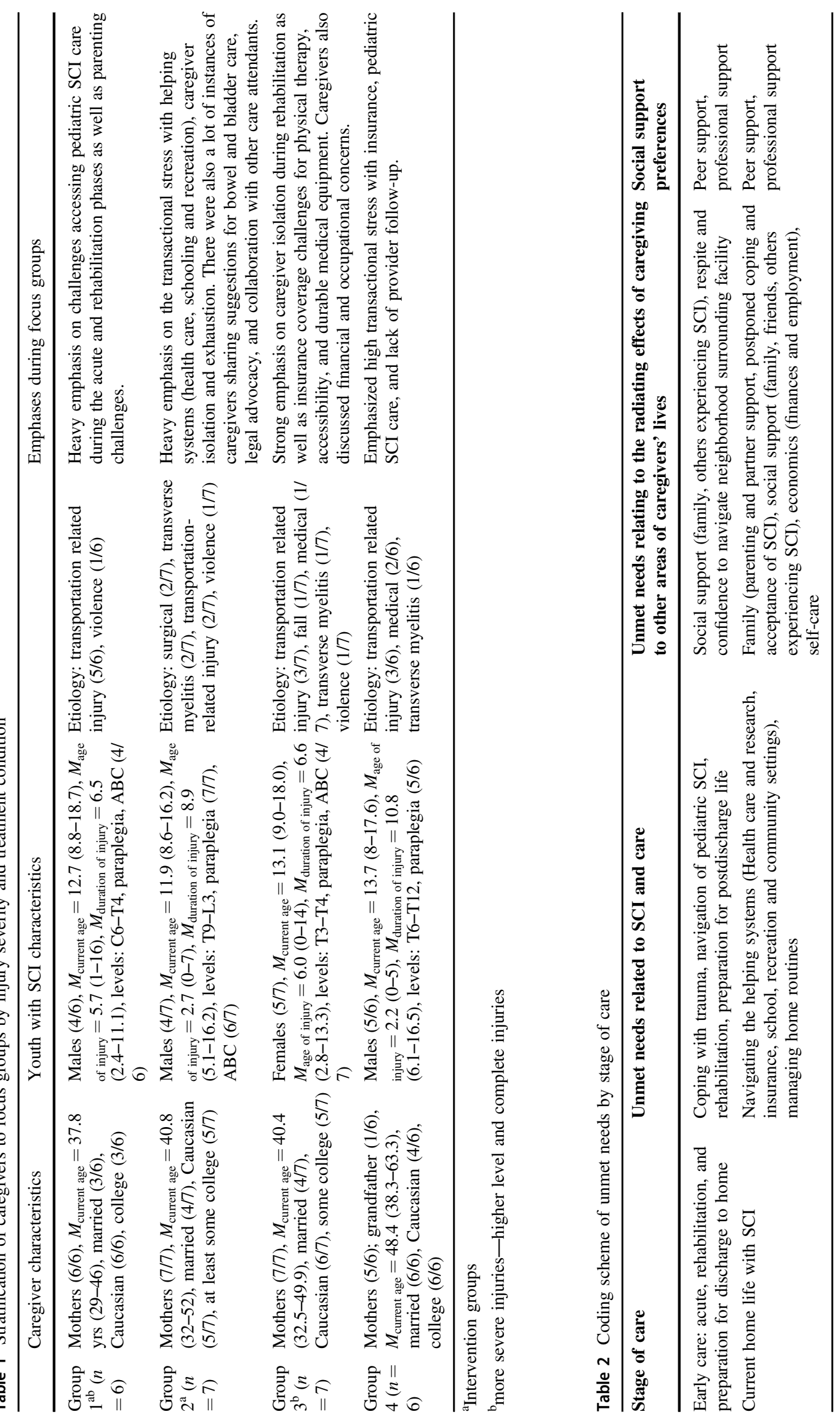


intervention group, (2) paraplegia and in the control group, (3) tetraplegia and in the intervention group, and (4) tetraplegia and in the control group. Table 1 summarizes the stratification and caregiver and youth characteristics for each group.

\section{The focus group guide}

The guide was developed to explore caregivers' unmet needs, support preferences, and experiences with the intervention. The focus groups lasted $1 \mathrm{~h}$, and approximately 5 min were devoted to introductions; 30 min to unmet needs; 10 to support preferences; and 15 to experiences with the intervention. The guide detailed ground rules for group participation and provided prompts for introductions, questions, and exploring domains of interest. Questions included: "Tell me about unmet needs you have as a caregiver of a child with a spinal cord injury?" with probes such as, "What aspects of your caregiving are you least confident about?" and "What are the areas that you are still struggling with as caregivers?" Open-ended follow-up questions were used to elicit additional detail and clarity around unmet needs. Facilitators used summary statements (verbal and written on large chart papers posted on the walls) as a member-checking strategy to clarify, gain more detail, assess consensus, and explore for unique experiences.

\section{Data collection}

The 4 focus groups were conducted simultaneously during the afternoon of the parent forum. The focus groups were digitally recorded and transcribed verbatim. The moderators and assistant facilitators were not involved in the design or implementation of the caregiver support intervention. Focus group moderators were doctoral level evaluators with specializations in community psychology and education. Assistants were individuals with varied undergraduate and graduate training.

\section{Data analysis}

Data analysis was iterative and involved multiple analysts (the focus group moderators, assistants, and authors of this study). Themes were initially documented on flip charts and reviewed during the focus groups with participants. After the focus groups, the moderators and facilitators debriefed and shared thematic highlights with each other. Coding occurred in two main stages.

The first stage of coding focused on summarizing caregiver responses around unmet needs and support preferences, and involved focus group moderators and assistants coding focus group transcripts using Krueger's Long Table Approach [32] and Microsoft Excel.
The second stage of coding focused on a broader organization of the data, as we noted that caregivers talked distinctly about 2 phases of care: (1) early care: acute care, rehabilitation, and preparation for discharge, and (2) current home life with SCI, and that unmet needs could be categorized into 2 types: (1) unmet needs related to SCI and care, and (2) unmet needs related to the radiating effects of caregiving to other areas of caregivers' lives, most prominently their families. Lastly, caregivers' social support preferences fell within two categories: (1) peer support for caregivers and their family members, and (2) professional care navigation. The lead author developed the coding scheme, coded transcripts in NVivo, and worked with a second coder to validate the coding scheme. The coding scheme and key themes are summarized in Table 2.

Of note, unmet needs did not appear to vary by injury severity or treatment condition, however, there were unique nuances and emphases among the groups, which are highlighted in Table 1. As is the nature of focus groups, the conversations varied depending on how group members chose to respond to questions. However, the themes presented below were consistently mentioned in all four groups.

\section{Results}

Data relating to unmet needs and support preferences are presented here according to the themes highlighted above. Further, subthemes are presented in order of frequency, where subthemes discussed more often by caregivers are listed first. Additional illustrative quotes are available in the Supplementary Table.

\section{Unmet Needs}

\section{Phase 1. Early care}

Unmet needs relating to $\mathrm{SCl}$ and care. Early care unmet needs focused most strongly on unmet needs relating to SCI and care. Caregivers described unmet needs relating to coping with trauma, navigating pediatric SCI care, and preparing for post-discharge life.

Coping with trauma: Caregivers described being in a traumatic state during the early diagnostic and acute treatment phase; they described the tremendous emotional anguish they felt about the children's injuries and consequences. As 1 caregiver stated, "You are not sure if your child is going to live or die." Caregivers reported that there was very little support for them to process the trauma. They described devoting all their energy to comforting their children and trying to figure out what could be done to help. Some caregivers also shared feelings of guilt and difficulties 
managing guilt, especially if they were present during the event that led to the SCI. They described feeling alone and pressured to put aside their needs to attend to the stabilization of their child.

Navigation of pediatric SCI care: Caregivers discussed frustrations they experienced finding rehabilitation facilities and services for children with SCI and the great efforts and time it took to have their child moved to a pediatric SCI rehabilitation setting, even when the pediatric center was near their child's acute care facility. Many had little to no help in navigating options. Caregivers talked about delays in accessing specific pediatric SCI rehabilitation care as contributing to delays in their child's access to braces and durable medical equipment (DME), delays in skill development (e.g., transfers, wheelchair skills), and development of secondary conditions like scoliosis.

Once in rehab, caregivers expressed challenges managing their emotions around SCI care. Caregivers reported that medical terminology was confusing and even offensive. In response to her child's injury being classified as "nontraumatic," 1 mother of a child with transverse myelitis commented that pediatric SCI is always traumatic, regardless of etiology. Caregivers described challenges processing and retaining the details of $\mathrm{SCI}$ and what was going on with their child's care and well-being. They also described feeling sad and frustrated that providers seemed to have low expectations for their child's recovery. For example, caregivers recalled providers stating that they should be happy that their child is alive, that they should not expect more progress as their child's injury was complete (vs. incomplete), and that certain more aggressive therapies were not worth it in the long run. One caregiver recalled feeling like providers attempted more aggressive therapies not because they believed they would help their child, but rather just to placate them as the caregiver.

Preparation for post discharge life: Caregivers reported feeling unprepared for discharge. Some caregivers described leaving rehab with basic community- and statelevel resource referrals that missed the mark on the immediacy of their needs, such as getting their children into the front door of their homes, acquiring essential equipment, gaining confidence with transfers and activities of daily living (ADLs), and navigating the world of benefits and social services.

\section{Unmet needs relating to other areas of caregivers' lives.}

While most of the unmet needs during the early stages after injury focused on the child's SCI and care, once in rehab, the unmet needs discussed by caregivers centered on isolation regarding social networks and physical space. Caregivers spoke of the profound isolation they felt from family and friends. Distance between home and the rehabilitation facility, competing life demands (employment and taking care of other children), and visiting restrictions often led to long separations from spouses. They also reported that they had few, if any, opportunities to talk with other parents of children with SCI. Caregivers also reported feeling physically disconnected from life outside of their child's rehabilitation facility, as many reported lacking knowledge about the neighborhood and/or access to local transportation resources. This reduced opportunities for respite or leisure for caregivers, but also for their recovering children. Some caregivers also reported accessibility barriers with public transportation and sidewalks around their child's rehabilitation facility.

\section{Phase 2. Current home life with $\mathrm{SCl}$}

Unmet needs relating to $\mathrm{SCl}$ and care. Caregivers discussed current unmet needs centering on SCI and care, including challenges navigating healthcare systems and community services as well as difficulties managing home routines.

Navigating services: Caregivers reported experiencing stress as they attempted to navigate and receive support from the many "helping" systems related to their child's ongoing life with SCI, including medical care, insurance, school, recreation, and community settings.

Related to medical care, caregivers discussed challenges with decentralized systems of care where caregivers described efforts to piece together care teams across multiple facilities, organizations, and geographic locations. Caregivers spoke of challenges keeping up with the high quantity of outpatient follow-up appointments across a variety of providers, including physiatrists, urologists, pulmonologists, and physical and occupational therapists. Many caregivers also recalled being told by providers that they could not seek care from multiple facilities, which seemed to be motivated by the providers' own business interests.

Some caregivers spoke of additional challenges finding healthcare providers experienced with girls, adolescents, and youth struggling with their emotional adjustment to SCI. Some also shared perceptions of care becoming less consistent and comprehensive as their child approached young adulthood, echoing earlier frustrations with lowered expectations for their child's ongoing care and rehabilitation and suggesting a possible lack of attention to the many transitions families of adolescents and young adults face.

Several caregivers spoke of ongoing uncertainty about their children's SCI and the circumstances leading up to the injury, particularly when the SCI occurred following a medical procedure or illness. These caregivers appeared to have several outstanding questions about how the injury 
occurred. They also alluded to trust concerns with medical providers.

Caregivers also discussed frustrations with the difficulty of keeping up with cutting edge research and medical treatments that may benefit their child, including therapies related to ambulation and bowel and bladder care developments. In describing her child with SCI breaking his leg during his participation in a research study, 1 caregiver reported uncertainty about investigators' expertize with SCI and oversight of safety for her child.

Relative to insurance, caregivers commonly described stressful transactions around coverage for DME and therapies for their children. It was common to hear confusion about current benefits and policies. Caregivers were frustrated with the limited availability of public benefits within their state, as well as the oftentimes confusing variation in benefits by state. A particular concern mentioned included lack of coverage for habilitative therapies. The caregivers discussed how because their children were injured at a young age they never had the chance to develop some skills prior to injury; now as a child with SCI, ongoing therapy was critical to the effective acquisition of these skills. Caregivers also discussed challenges updating equipment following growth spurts if insufficient time had passed for replacement/resizing per their insurance policies. Coverage for DME to foster community participation also appeared to be challenging and stressful (e.g., bikes and aids to get in and out of homes and vehicles, etc.).

Relative to education, caregivers described challenges securing educational opportunities in classrooms with typically developing peers, as well as challenges securing help from trained assistants and advocates knowledgeable about SCI. Several parents discussed that home schooling was their only viable option for fostering their child's education given the lack of understanding and capacity in the schools and the high number of outpatient medical appointments their children required. One caregiver in particular stated that home schooling was a last resort after being threatened with truancy court because of excessive health-related absences that the school refused to document as excused.

Caregivers discussed challenges finding recreational activities for their children. They described that their children were often "lumped together" with other youth living with disabilities, most commonly cognitive disabilities. While these opportunities were often physically accessible, caregivers reported that they were not necessarily enriching programming for their children. They discussed that such grouping led to stigma, misinformation about SCI, limited fitness and recreational opportunities appropriate for their children, and lack of school and community social opportunities with typically developing peers or other peers with physical disabilities.

An unmet need that impacted both school and recreation was the lack of availability of accessible bathrooms in communities and schools. Caregivers discussed that not all facilities have family bathrooms available to caregivers of both sexes with changing spaces that can support the weight of a larger child (beyond a toddler). They explained that this limited inclusion of their children in field trips and other community activities.

Managing home routines: Caregivers reported many unmet needs managing home routines. Caregivers often described that the quantity, frequency, and intimacy of ADLs and home care regimens, including stretching, bowel and bladder programs, bathing, and menstrual care, are areas of high stress and often beyond their abilities, mostly because of time and energy. Related to this, caregivers alluded to the stress they feel around the need to routinely monitor secondary conditions and concerns (e.g., autonomic dysreflexia, body temperature, urinary tract infections, pressure injuries, etc.). Many caregivers voiced concerns and guilt for not keeping up with their children's care regimens. There was a strong sense that caregivers did not forgive themselves when their efforts fell short of their own expectations. Caregivers alluded to an internal struggle between wanting to do as much as possible for their children and fostering their independence.

Caregivers appeared willing to involve care assistants but struggled to find support. Many said family members and daycare providers were reluctant to provide care to their children with SCI. Some caregivers spoke of challenges training supplemental care providers but others spoke of how helpful and well worth their efforts it had been. One caregiver shared how the paid assistant helps with their child's bathing and bowel and bladder program, and this frees her up to be "mom first." However, it is important to note that many caregivers were puzzled about how to afford supplemental care assistants.

\section{Unmet needs relating to other areas of caregivers' lives}

Caregivers talked most frequently about unmet needs related to their families, but unmet needs in other areas of their lives related to social networks, economics, and self-care.

Family. Caregivers frequently spoke of challenges balancing their caregiving duties with other family roles including parenting and marital/partner relations. Caregivers described feeling like their caregiving role has overshadowed their parenting role, related both to their child with SCI and their other children. Several also spoke of challenges in their relationships with significant others/ partners. They described experiencing restricted time with 
their significant other, and at times, separations and divorce. Many of the caregivers reported that the time and stress associated with caregiving took an even greater toll on their marriages and partnerships than the stressors that usually accompany family life.

Several caregivers reported ongoing challenges for all in the family related to coping with and accepting life with SCI, particularly for their child with SCI and his/her siblings. Families appeared to have established new routines in the years following the injury but still struggled with the emotional trauma of SCI, particularly for those who observed the injury or were present during the early phase of care. Caregivers also stated that they have had challenges finding mental health providers who can support their family's adjustment to their child's injury.

Social network disruptions. Parents reported that their children living with SCI faced challenges bonding and developing relationships with typically developing peers and having very limited to no access to other youth living with physical disabilities. Parents also described feeling disconnected from extended family members and friends. Many described how they pushed everyone away during the early stage of SCI, and how they now struggled with reaching back out to friends and families. Some stated they had a hard time relating to friends. Other caregivers described extended family members being afraid to help for fear of hurting their child with SCI, which then limited their time together and reduced chances of supplemental care support from family members.

Economics. Caregivers described significant financial stress as they tried to cover medical care and equipment, make modifications to their homes and vehicles, afford supplemental care, and pay for family vacations. Caregivers also described lost income due to leaving their careers to provide care to their child with SCI. Lastly, finding flexible jobs was a stressor for those caregivers desiring some employment outside of the home.

Self-care. While caregivers readily discussed impacts of caregiving duties on family routines, it took more probing by facilitators for caregivers to discuss how the lack of time and stamina impacted attention to their own self-care needs. As one example of the lack of attention typically afforded to their own needs, a number of caregivers stated that their participation in the parent forum provided them a first opportunity of respite from the care demands and life stressors since their child was diagnosed with SCI. They described how wonderful it was that someone else was responsible for the details, managed everything, and took tremendous effort to care for them and to treat them to such a special time. Caregivers had similar reactions to the focus groups themselves, as they expressed appreciation for the opportunity to share their perceptions, and actively engaged in conversations with other caregivers. These responses highlighted caregivers' typical lack of attention towards self-care, and their need for validation, relaxation, and respite.

\section{Support preferences}

\section{Professional support}

Caregivers articulated a need for more support from professionals during the initial treatment and rehabilitation phase. They described feeling overwhelmed and needing help processing all the information they were receiving and emotions they were experiencing. Some stated that it would be nice to have a specific support person to meet with individually and, when possible, in a group with multiple caregivers. Some specifically mentioned someone like a care coordinator to follow-up with, someone who could help them process information, triage emerging care needs, and provide ongoing coordination between primary and specialty care providers. Caregivers also stated that they wish they could have received more information to use immediately following discharge, particularly in terms of specialty care, home care and strategies for maintaining routines, prevention of secondary conditions, insurance, and navigating community integration (schooling, recreation, etc.). Caregivers articulated diverse perspectives on the best format for this information; some expressed a desire for the information in writing (in a big binder) and others stated they would like information to be posted online.

\section{Peer support}

Caregivers were unanimous in the need for more peer support. Caregivers spoke of the power of hearing and receiving support from others who have "been there and done that." They would like organizations to help connect families to one another. During the focus groups themselves there was evidence of peer support: caregivers provided each other with information and support around legal issues, educational concerns, recreation resources, accessible vacation options, financial aid, insurance and benefits, care strategies, parenting, care and treatment procedures (in particular around bowel and bladder care), and self-care. Moreover, caregivers spoke of wanting to find marriage, family, and/or youth retreat or camp options to have respite time with others living with SCI.

\section{Discussion}

The current study is the first to qualitatively explore the unmet needs and support preferences of caregivers of youth with SCI. There is a long history of examining the mental 
health of families living with disabilities. Less attention has been paid, however, to preventing mental health issues and to the development and evaluation of interventions that can bolster the supports needed to promote caregiver and family resiliency $[7,35,36]$.

Data from the current study offer a start to understanding the timing of unmet needs and the nature of stressors experienced by caregivers of youth with SCI; together data highlight opportunities for future research and interventions. Primary stressors that were identified included needs related to coping with trauma, navigating pediatric SCI care and ancillary services and systems, and preparing for and then maintaining home care routines. Identified secondary stressors included impacts on the family (including balancing roles and emotional distress), social networks, financial stability, and the caregivers' own self-care. Data also highlighted support from both professionals and peers as resources that could potentially serve as mediators between stressors and caregiver well-being; this builds on past research that has identified the importance of caregiver problem solving skills $[3,22]$. Fleshing out these components of stress theory model in the specific context of caregiving and pediatric SCI can help lead to the development of comprehensive models of intervention to support caregivers of youth with SCI.

The themes expressed here, including high stress in dealing with helping systems, challenges coping emotionally with traumatic injuries, radiating effects of caregiving to other life domains, and a lack of social supports, are not necessarily new to the caregiving literature [23, 35-37]. What is critical to understand, however, is the ongoing nature of these unmet needs for these families. On average, participating families had been coping with life with SCI for 8 years. Their narratives suggest there is a need to develop and strengthen ongoing family-centered systems of care and interventions in pediatric rehabilitation [31, 38-41]. Specific to pediatric injuries, children cycle through a variety of developmental stages and deal with their injuries differently over time. Throughout these stages, youth with SCI, their caregivers, and family members need ongoing support to bolster coping with the injury, navigating care and services, and maintaining self-care and a sense of normalcy for one's family [42]. Incorporating instrumental support to help families navigate these challenges has the promise of reducing stress and fostering healthy adaptation. In particular, healthcare and rehabilitation models should be informed by trauma-informed care practices [43], including universal risk assessment and multidisciplinary care that is aimed at reducing acute stress within all families. This can be coupled with cognitive and behavioral interventions to reduce traumatic stress symptoms for those exhibiting heightened distress. Even when families re-emerge from the crisis of pediatric SCI relatively intact, they still face a marathon over the long haul to support their children's and family's needs.

The stress participating caregivers experienced when dealing with helping systems seemed so intense that it deserves particular attention. Similar to what Wuest and colleagues found with female carers [44, 45], the caregivers in our focus groups, also predominately mothers, alluded to health care, research, insurance, and communities as helping systems that are designed to support families in need. However, they were routinely frustrated and disillusioned by a lack of support to help them navigate complex systems, as well as language and attitudes from some providers and staff that they experienced as non-caring. Narrative data often suggested that the adversity experienced by many caregivers within these helping systems was akin to secondary victimization [46]. Improving access and quality of care, and increasing the fit between needs and services, are important elements with potential to reduce family burden [43-45, 47]. Providers should assess caregivers' strengths and challenges in processing information, provide information in a variety of formats, and be resilient enough to see past any frustration or negative responses from caregivers in order to provide the support that families need. Support should be provided to providers in the form of initial training and ongoing support to decrease burnout and minimize frustration.

Finally, this study adds to the research on the importance of peer groups and peer support for patients and family members engaged in SCI care and rehabilitation [48, 49]. Throughout the focus groups, caregivers were able to not only express their needs in their own words, but they were able to interact and share their experiences with one another. In addition to providing critical information to clinicians and researchers, the focus group format provided caregivers with a safe place to express their needs and experiences and provide support to each other.

\section{Implications for future research and practice}

Several implications emerged for future work, including research, theory refinements, clinical practice, and health care policy. First, there is a need for more qualitative research exploring needs and perspectives from caregivers' perspectives, including multiple parents, caregivers, and siblings within families. This study demonstrates the strength of focus groups, where caregivers are together and able to provide each other with needed supports, while also sharing critical information with researchers. This research is additive to understanding family perspectives on unmet needs, as well as involving families in helping to shape research studies and health care programs [50-52]. In addition to the need for the development and evaluation of a variety of pediatric caregiver-focused interventions, this 
research adds to the calls for more service and research attention on families $[3,4,14,15]$ including youth who live with chronically ill siblings $[4,53,54]$.

Specific to theory, while the stress theory model provided an initial useful framework for exploring unmet needs of pediatric SCI family caregivers, the model highlights stress process from the caregiver perspective and does not adequately capture family stress processes. Future research on family caregiving and pediatric SCI would be well served by integrating family perspectives, parenting and parenting stress theory into models on caregiving stress $[2,55,56]$.

Specific to practice, and in particular clinical care during the child's early acute care and rehabilitation, several families suggested the need for parental support during long and often initially chaotic inpatient stays. Support is needed to process the large quantity of information they are faced with, provide insight into what adjustment and life following SCI looks like, and combat the isolation they feel, particularly on weekends. Perhaps health care facilities can work to provide staff or volunteer support during these times for caregivers so they do not feel so alone. Another comment pointed to the need to allow more than 1 caregiver to stay by a child's bedside. If this is not feasible, perhaps the second caregiver can stay elsewhere in the hospital (in a hotel-type environment) and carry a pager so he or she can easily be reached. In addition, caregiver perspectives on the trauma and chaos of SCI suggest that many could benefit from follow-up professional support to digest the ongoing implications of the injury at different life stages, and navigate lifelong transitions and care needs. Moreover, respite and peer support could foster adjustment to life after SCI.

\section{Limitations}

This study included several limitations. First, the convenience sample consisted mostly of females, specifically mothers, from North America. Therefore, the personal experiences and unmet needs shared may not reflect those of fathers or other types of caregivers including those living in other regions of the world. In addition, caregiver participants were primarily recruited from 1 health care facility that served youth with SCI. Therefore, the experiences of other caregivers who have children with SCI who do not have access to or communication with this facility are not captured in this research study. In addition, the children of participating caregivers had been injured between 2 and 16 years ago. Therefore, these caregivers' experiences of the acute phase of care may not represent those of families who have more recent injuries. However, anecdotal reports have echoed more recent caregiver perceptions of acute care as chaotic. Furthermore, the current sample of caregivers was highly educated, and it may be that they experienced different types of needs as compared to caregivers of youth with SCI with less education. These caregivers were also all able to travel to the hospital for the intervention described above. Although the study funded all expenses related to travel, the travel requirement reportedly prohibited some caregivers from participating. Finally, the groups were only $1 \mathrm{~h}$ in length and ran simultaneously, so we cannot be assured that we reached saturation. However, saturation is not just about numbers but also the depth of the data [57, 58]; no new coding emerged from one group to the next, and the 4 groups generated thick description. Program and intervention development would benefit from additional qualitative data collection with similar and distinct caregivers of youth with SCI.

\section{Conclusion}

Caregivers poignantly articulated a number of unmet needs relative to the acute and rehabilitation phases of care through ongoing maintenance of SCI. Caregivers also articulated a need for more social support, from both professionals and peers. In the spirit of discussions of familycentered care and providing youth with special health care needs specialized care within medical neighborhoods [47], it is imperative that we search for opportunities to provide caregiver services as part of our commitment to serving youth. While more research is needed to understand how best to meet their needs, this study provided an important first step in terms of understanding the unmet needs of a sample of caregivers of youth with SCI.

Acknowledgements We extend our sincere appreciation to the families who participated in this research or supported loved ones so that they could participate. We are in debt to Titilope Akinlose, Consuella Brown, Mimi Doll, Molly Kane, Denise Roseland, Norma Seledon, and Carly Wesolowski for data collection and early analysis support. We also extend our gratitude to Kerry O'Rourke for her editing assistance. This research was funded by the Craig H. Neilsen Foundation, Grant \# 288993. The study protocol was approved by the Institutional Review Board of Rush University and ethical procedures were followed in regard to the treatment of human subjects and reporting of all research procedures and findings.

\section{Compliance with ethical standards}

Conflict of interest The authors declare that they have no competing interests.

\section{References}

1. Eastwood E, Hagglund K, Ragnarsson K, Gordon W, Marino R. Medical rehabilitation length of stay and outcomes for persons with traumatic spinal cord injury-1990-1997. Arch Phys Med Rehabil. 1999;80:1457-63. doi: 10.1016/S0003-9993(99)90258-7.

2. Cousino M, Hazen R. Parenting stress among caregivers of children with chronic illness: a systematic review. J Pediatr Psychol. 2013;38:809-28. https://doi.org/10.1093/jpepsy/jst049. 
3. Kelly E, Riordan A, Zebracki K, Thorpe S, Vogel L. Relationships between caregiver characteristics and health-related QOL among youth with spinal cord injury. Top Spinal Cord Inj Rehabil. 2016;22:149-57. https://doi.org/10.1310/sci2016-00012.

4. Akhtar M, Kennedy P, Webster G, Graham A. What about us? Children's experiences of living with a sibling with spinal cord injury. J Pediatr Rehabil Med. 2012;5:301-13. https://doi.org/10. 3233/PRM-2012-00226.

5. Elliott T, Shewchuk R. Recognizing the family caregiver: integral and formal members of the rehabilitation process. J Vocat Rehabil. 1998;10:123-32. https://doi.org/10.3233/JVR-1998-10206.

6. Hart G. Spinal cord injury: impact on clients' significant others. Rehabil Nurs. 1981;6:11-5. https://doi.org/10.1002/j.2048-7940. 1981.tb01389.x.

7. Kazak AE. Families of chronically ill children: a systems and social-ecological model of adaptation and challenge. J Consult Clin Psychol. 1989;57:25-30. https://doi.org/10.1037/0022-006X. 57.1.25.

8. Lazarus RS, Folkman S. Stress, appraisal, and coping. New York, NY: Springer Publishing Co; 1984.

9. Pearlin LI, Mullan JT, Semple SJ, Skaff MM. Caregiving and the stress process: an overview of concepts and their measures. Gerontologist 1990;30:583-94. https://doi.org/10.1093/geront/30.5. 583.

10. Aneshensel CS, Pearlin LI, Mullan JT, Zarit SH, Whitlatch CJ. Profiles in caregiving: the unexpected career. Cambridge MA: Academic Press; 1995.

11. Stamataki Z, Ellis JE, Costello J, Fielding J, Burns M, Molassiotis A. Chronicles of informal caregiving in cancer: using 'The cancer family caregiving experience model as an explanatory framework. Support Care Cancer 2014;22:435-44. https://doi.org/10.1007/ s00520-013-1994-1.

12. Blanes L, Carmagnani M, Ferreira L. Health-related quality of life of primary caregivers of persons with paraplegia. Spinal Cord 2007;45:399-403. https://doi.org/10.1038/sj.sc.3102038.

13. Boschen K, Tonack M, Gargaro J. The impact of being a support provider to a person living in the community with a spinal cord injury. Rehabil Psychol. 2005;50:397-407. https://doi.org/10. 1037/0090-5550.50.4.397.

14. Boyer B, Knolls M, Kafkalas C, Tollen L, Swartz M. Prevalence and relationships of posttraumatic stress in families experiencing pediatric spinal cord injury. Rehabil Psychol. 2000;45:339-55. https://doi.org/10.1037/0090-5550.45.4.339.

15. Dasch K, Russell H, Kelly E, Gorzkowski JA, Mulcahey MJ, Betz $\mathrm{RR}$, et al. Coping in caregivers of youth with spinal cord injury. J Clin Psychol Med Settings 2011;18:361-71. https://doi.org/10. 1007/s10880-011-9258-z.

16. Post M, Bloemen J, de Witte L. Burden of support for partners of persons with spinal cord injuries. Spinal Cord 2005;43:311-9. https://doi.org/10.1038/sj.sc.3101704.

17. Raj J, Manigandan C, Jacob K. Leisure satisfaction and psychiatric morbidity among informal carers of people with spinal cord injury. Spinal Cord 2006;44:676-9. https://doi.org/10.1038/ sj.sc.3101899.

18. Ünalan $\mathrm{H}$, Gencosmanoglu $\mathrm{B}$, Akgün $\mathrm{K}$, Karamehmetoglu S, Tuna $\mathrm{H}$, Önes $\mathrm{K}$, et al. Quality of Life of primary caregivers of spinal cord injury survivors living in the community: controlled study with short form-36 questionnaire. Spinal Cord 2001;39:318-22. https://doi.org/10.1038/sj.sc.3101163.

19. Weitzenkamp DA, Gerhart KA, Charlifue SW, Whiteneck GG, Savic G. Spouses of spinal cord injury survivors: The added impact of caregiving. Arch Phys Med Rehabil. 1997;78:822-7. doi: 10.1016/S0003-9993(97)90194-5.

20. Kelly E, Anderson C, Garma S, Russell HF, Klaas SJ, Gorzkowski JA, et al. Relationships between the psychological characteristics of youth with spinal cord injury and their primary caregivers. Spinal Cord 2011;49:200-5. https://doi.org/10.1038/ sc. 2010.78

21. Garma SI, Kelly EH, Daharsh EZ, Vogel LC. Health-related quality of life after pediatric spinal cord injury. J Pediatr Psychol. 2011;36:226-36. https://doi.org/10.1093/jpepsy/jsq037.

22. Elliott TR, Shewchuk RM, Richards JS. Caregiver social problemsolving abilities and family member adjustment to recent-onset physical disability. Rehabil Psychol. 1999;44:104-23. https://doi. org/10.1037/0090-5550.44.1.104.

23. Aitken ME, Mele N, Barrett KW. Recovery of injured children: parent perspectives on family needs. Arch Phys Med Rehabil. 2004;85:567-73. https://doi.org/10.1016/j.apmr.2003.06.018.

24. Vargo F. Adaptation to disability by the wives of spinal cord injured males-a phenomenological approach. J Rehabil Counsel. 1984;15:28-32.

25. Wharewera-Mika J, Cooper E, Kool B, Pereira S, Kelly P. Caregivers' voices: The experiences of caregivers of children who sustained serious accidental and non-accidental head injury in early childhood. Clin Child Psychol Psychiatry 2016;21:268-86. https://doi.org/10.1177/1359104515589636.

26. Curry L, Nembhard I, Bradley E. Qualitative and mixed methods provide unique contributions to outcomes research. Circulation 2009;119:1442-52. https://doi.org/10.1161/ CIRCULATIONAHA.107.742775.

27. Green J, Britten N. Qualitative research and evidence based medicine. BMJ 1998;316:1230-2. https://doi.org/10.1136/bmj. 316.7139.1230.

28. Kirchberger I, Sinnott A, Charlifue S, Kovindha A, Luthi H, Campbell R, et al. Functioning and disability in spinal cord injury from a consumer perspective: an international qualitative study using focus groups and the ICF. Spinal Cord 2010;48:603-13. https://doi.org/10.1038/sc.2009.184.

29. Mays N, Pope C. Qualitative research in health care: assessing quality in qualitative research. Br Med J. 2000;320:50-2. https:// doi.org/10.1136/bmj.320.7226.50.

30. Whalley Hammell K. Experience of rehabilitation following spinal cord injury: a meta-synthesis of qualitative findings. Spinal Cord 2007;45:260-74. https://doi.org/10.1038/sj.sc.3102034.

31. Shewchuk RM, Franklin FA, Harrington KF, Davies SL, Windle M. Using cognitive mapping to develop a community-based family intervention. Am J Health Behav. 2004;28:43-53. https:// doi.org/10.5993/AJHB.28.1.5.

32. Krueger RA, Casey MA (2000) Focus Groups. A practical guide for applied research. 3rd ed. SAGE Publications, Thousand Oaks, CA.

33. Stewart DW, Shamdasani PN (1990) Focus Groups. Theory and Practice. Applied Social Research Methods Series.Series. SAGE Publications, Newbury Park, CA, Vol. 20.

34. Rivelli A, Kelly EH, Ryerson Espino S, Vogel LC. (In Press). Development of the Parent Forum: An In-Person Approach to Supporting Caregivers of Youth with Spinal Cord Injury. The Journal of Spinal Cord Medicine.

35. Smith EM, Boucher N, Miller WC. Caregiving services in spinal cord injury: a systematic review of the literature. Spinal Cord 2016;54:562-9. https://doi.org/10.1038/sc.2016.8.

36. Meade M, Taylor L, Kreutzer J, Marwitz J, Thomas V. A preliminary study of acute family needs after spinal cord injury: analysis and implications. Rehabil Psychol. 2004;49:150-5. https://doi.org/10.1037/0090-5550.49.2.150.

37. Baker A, Barker S, Sampson A, Martin C. Caregiver outcomes and interventions: a systematic scoping review of the traumatic brain injury and spinal cord injury literature. Clin Rehabil. 2017;31:45-60. https://doi.org/10.1177/0269215516639357.

38. Fowler S. Neurotrauma family interventions. J Trauma Nurs. 1997;4:68-73. 
39. Hoy L. A mother's journey from the roadside to the operating room. J Perioper Pract. 2013;23:153-4.

40. Kirk S, Fallon D, Fraser C, Robinson G, Vassallo G. Supporting parents following childhood traumatic brain injury: a qualitative study to examine information and emotional support needs across key care transitions. Child Care Health Dev. 2015;41:303-13. https://doi.org/10.1111/cch.12173.

41. Aitken ME, McCarthy ML, Slomine BS, Ding R, Durbin DR, Jaffe KM, et al. Family burden after traumatic brain injury in children. Pediatr. 2009;123:199-206. https://doi.org/10.1542/ peds.2008-0607.

42 Harrington B, Harrington M, McCreary J, Russel H. Life with a spinal cord injury: From the parents', daughter's and clinician's perspective. In: Vogel LC, Zebracki K, Betz RR, Mulcahey MJ, eds. Spinal Cord Injury in the Child and Young Adult. London, UK: Mac Keith Press; 2014: 3-14.

43. Kazak AE, Rourke M, Alderfer MA, Pai AL, Reilly A, Meadows AT. Evidence-based assessment, intervention and psychosocial care in pediatric oncology: a blueprint for comprehensive services across treatment. J Pediatr Psychol. 2007;32:1099-110. https:// doi.org/10.1093/jpepsy/jsm031.

44. Wuest J. Fraying connections of caring women: an exemplar of including difference in the development of explanatory frameworks. Can J Nurs Res. 1997;29:99-116.

45. Wuest J. Illuminating environmental influences on women's caring. J Adv Nurs. 1997;26:49-58.

46. Campbell R, Barnes H, Ahrens C, Wasco S, Zaragoza-Diesfeld Y, Sefl T. Community services for rape survivors enhancing psychological well-being or increasing trauma? J Consult Clin Psychol. 1999;67:847-58. https://doi.org/10.1037/0022-006X.67.6.847.

47. Taylor E, Lake T, Nysenbaum J, Peterson G, Myers D. Coordinated care in the medical neighborhood: critical components and available mechanisms. Rockville, MD: Agency for Healthcare Research and Quality; 2011. https://pcmh.ahrq.gov/sites/default/ files/attachments/Coordinating\%20Care\%20in\%20the\%20Medica $1 \% 20$ Neighborhood.pdf.

48. Beauchamp MR, Scarlett LJ, Ruissen GR, Connelly CE, McBride $\mathrm{CB}$, Casemore $\mathrm{S}$, et al. Peer mentoring of adults with spinal cord injury: a transformational leadership perspective. Disabil Rehabil. 2016;38:1884-92. https://doi.org/10.3109/09638288. 2015.1107773 .
49. Haas BM, Price L, Freeman JA. Qualitative evaluation of a community peer support service for people with spinal cord injury. Spinal Cord 2013;51:295-9. https://doi.org/10.1038/sc.2012.143.

50. Middleton JW, Piccenna L, Lindsay Gruen R, Williams S, Creasey G, Dunlop S, et al. Developing a spinal cord injury research strategy using a structured process of evidence review and stakeholder dialogue. Part III: outcomes. Spinal Cord 2015;53:729-37. https://doi.org/10.1038/sc.2015.87.

51. Bragge P, Piccenna L, Middleton J, Williams S, Creasey G, Dunlop S, et al. Developing a spinal cord injury research strategy using a structured process of evidence review and stakeholder dialogue. Part II: background to a research strategy. Spinal Cord 2015;53:721-8. https://doi.org/10.1038/sc.2015.86.

52. Bragge P, Piccenna L, Middleton J, Williams S, Creasey G, Dunlop S, et al. Developing a spinal cord injury research strategy using a structured process of evidence review and stakeholder dialogue. Part I: rapid review of SCI prioritisation literature. Spinal Cord 2015;53:714-20. https://doi.org/10.1038/sc.2015.85.

53. Guggemos A, Juen F, Engelmann L, Diesselhorst V, Henze G, Di Gallo A. Siblings of children with cancer-the price they pay to function. Support Care Cancer 2015;23:1837-9. https://doi.org/ 10.1007/s00520-015-2716-7.

54. Sharpe D, Rossiter L. Siblings of children with a chronic illness: a meta-analysis. J Pediatr Psychol. 2002;27:699-710. https://doi. org/10.1093/jpepsy/27.8.699.

55. Muscara F, Burke K, McCarthy MC, Anderson VA, Hearps SJC, Hearps SJ, et al. Parent distress reactions following a serious illness or injury in their child: a protocol paper for the take a breath cohort study. BMC Psychiatry 2015;15:153. https://doi.org/10. 1186/s12888-015-0519-5.

56. Watson SL, Hayes SA, Radford-Paz E. "Diagnose me please!": a review of research about the journey and initial impact of parents seeking a diagnosis of developmental disability for their child. In: International review of research in developmental disabilities. 2011;41:31-71. https://doi.org/10.1016/B978-0-12-386495-6.00002-3.

57. Burmeister E, Aitken LM. Sample size: how many is enough? Australian Critical Care. 2012;25:271-4. https://doi.org/10.1016/j. aucc.2012.07.002.

58. Fusch PI, Ness L. Are we there yet? Data saturation in qualitative research. The Qual Report. 2015;20:1408-16. http://www.nova. edu/ssss/QR/QR20/9/fusch1.pdf. 